\title{
Relation of Cholesterol Metabolism and Non-Cholesterol Sterols to Insulin Resistance
}

\author{
A. ŠMAHELOVÁ ${ }^{1}$, R. HYŠPLER ${ }^{1}$, T. HAAS $^{2}$ \\ ${ }^{1}$ Department of Metabolic Care and Gerontology, University Hospital, Charles University, Hradec \\ Králové, Czech Republic and ${ }^{2}$ Third Department of Internal Medicine, First Medical Faculty, \\ Charles University, Prague, Czech Republic \\ Received July 13, 2006 \\ Accepted September 25, 2006 \\ On-line available November 6, 2006
}

\begin{abstract}
Summary
Using non-cholesterol sterols investigation several authors postulated a hypothesis that in the metabolic syndrome cholesterol endogenous synthesis is increased and its absorption decreased. Our study is the first attempt to evaluate the direct relation of cholesterol metabolism to the principal pathogenetic phenomenon of the metabolic syndrome - namely to insulin resistance. We have measured insulin sensitivity by two methods - Quicki (Quantitative Sensitivity Check Index) and intravenous insulin tolerance test (Kitt) and 3 indirect markers - fasting insulin level, fasting C-peptide level and SHBG (sex hormone binding globulin). The investigation was performed in three groups of subjects with a different prevalence of insulin resistance: 72 non-diabetics with ischemic heart disease, 117 young blood donors and 63 type 2 diabetics on diet therapy only. Analyzing altogether 60 relationships - between four sterols (lathosterol, squalene, sitosterol and campesterol) and five markers of insulin resistance in three groups of subjects - we have found only six significant relations between cholesterol synthesis and absorption and insulin resistance in all groups of patients. Our results indicate that there exists a significant relationship between insulin sensitivity and indices of either increased cholesterol synthesis or decreased cholesterol absorption. Insulin resistance explains only a part of both abnormalities mentioned above.
\end{abstract}

\section{Key words}

Non-cholesterol sterols $\bullet$ Plant sterols $\bullet$ Metabolic syndrome $\bullet$ Cholesterol absorption $\bullet$ Cholesterol synthesis

\section{Introduction}

All steroids created in the body are derived from cholesterol. Actual cholesterol levels are a result of intestinal cholesterol absorption, whole body cholesterol synthesis and cholesterol catabolism and excretion. The average daily intake of total cholesterol is 400-500 $\mathrm{mg}$. The rate of endogenous synthesis is $9-12 \mathrm{mg} / \mathrm{kg}$ body weight per day. A 70-kg man synthesizes about $700 \mathrm{mg}$ cholesterol per day (Brody 1999).

The endogenous cholesterol synthesis can be determined by the measurement of levels of its precursors - mainly lathosterol and partly squalene. The amount of cholesterol precursors incorporated in plasma lipoproteins depends on their production rate during cholesterol synthesis (Miettinen et al. 1990, Kuksis 2001). Kempen et al. (1988) used lathosterol to monitor the total body cholesterol synthesis. Plant sterols (campesterol and 
sitosterol) are absorbed proportionally to the absorption of cholesterol. The measurement of plant sterol levels can thus be considered clinically as a marker of cholesterol absorption. The standards for the measurement of cholesterol absorption and synthesis are based on balance and isotope methods. The cholesterol balance is based on the measurement of the amount of cholesterol ingested in food and excreted in the stool or as the amount of bile acids using gas chromatography. The serum levels of sitosterol and campesterol correlate with these methods (Miettinen 1970, Miettinen et al. 1990).

Simonen et al. (2002a,b,c) studied plant sterol levels in association with body weight in type 2 diabetics and concluded that the cholesterol absorption could be lowered by increasing insulin resistance. In order to maintain normal cholesterol levels, as seen in metabolic syndrome patients, the endogenous synthesis of cholesterol could be increased. We have also confirmed higher synthesis and lower cholesterol absorption in type 2 diabetics (Šmahelová et al. 2004). This fact explains the good response to statin treatment in type 2 diabetes (Šmahelová et al. 2005). Thus, the insulin resistance is supposed to be the main cause of the metabolic syndrome (Reaven 1988).

In this study we have measured insulin resistance using five different methods or markers and we analyzed the relationship of non-cholesterol sterols to the insulin resistance. Based on the above-mentioned data, we evaluated hypothesis that the decreased absorption of cholesterol and the compensatory increase of its synthesis could be directly influenced by the insulin resistance hypothesis of Simonen et al. (2000).

\section{Patients and Methods}

\section{Studied population and experimental design}

The investigation was performed in three groups of subjects (Table 1): 72 non-diabetics (non-DM) with ischemic heart disease, who were admitted into the internal department for elective coronarography a typical population with higher prevalence of insulin resistance, 117 young blood donors (BD) - population with low prevalence of insulin resistance and 63 type 2 diabetics (DM) currently on a diet, treated in the outpatient clinic - typical population with insulin resistance. The aim of the study was to use very different incomparable groups of subjects and to evaluate the relationship of cholesterol metabolism and insulin sensitivity in each group separately.
The dietary habit in all three groups of patients was examined anonymously with the simple questionnaire Fat and Fiber Behavior Questionnaire (Kristal et al. 1990). In all patients, serum levels of cholesterol, LDL-cholesterol, HDL-cholesterol, glucose, glycosylated hemoglobin $\mathrm{HbA}_{1} \mathrm{c}$, triacylgylcerols, lathosterol, squalene, sitosterol and campesterol were determined in the morning in the fasting state. The insulin tolerance test was performed on the same day.

The aim of the study was to evaluate the relation to actual insulin sensitivity independently of the cause of insulin resistance. Therefore, no drug influences were analyzed. There were 15 non-diabetics with ischemic heart disease and 15 diabetics treated with atorvastatin and the majority of patients was treated for hypertension. Patients with severe diseases (cancer, cirrhosis, organic gastrointestinal diseases and acute vascular disease) were excluded.

\section{The insulin resistance evaluation}

The standard of insulin resistance evaluation is the glucose clamp method (DeFronzo et al. 1979). However, this method cannot be used in common clinical practice. We used two simpler methods to evaluate the insulin resistance:

- Quicki (Quantitative Sensitivity Check Index) which was determined by formula $1 /\left(\ln \mathrm{G}_{0}+\ln \mathrm{I}_{0}\right)$ where $\mathrm{G}_{0}$ is mean fasting plasma glucose in mmol/1, $\mathrm{I}_{0}$ fasting serum insulin in mU/l ( $\breve{S k r h a}$ et al. 2004). Quicki index is one of many indexes based on glucose and insulin values. All these indexes have limited significance in diabetics where the insulin secretion failure is already present.

- Intravenous insulin tolerance test after intravenous insulin dose of $0.05 \mathrm{U} / \mathrm{kg}$ body weight (Bonora et al. 1989, Hirst et al. 1993 Graci et al. 1999). This test was not used in the group with the ischemic heart disease, where it is contraindicated. Blood glucose was evaluated in the $3^{\text {rd }}$ and $15^{\text {th }}$ minute. Index of the insulin sensitivity (Kitt) was calculated according to formula: $\mathrm{K}_{\mathrm{itt}}=\left(\ln _{3 \min }-\ln _{15 \min }\right) / \mathrm{t}(\mathrm{t}=12 \mathrm{~min}$ in this case). Thus for a patient having the glucose levels $6.51 \mathrm{mmol} / \mathrm{l}$ and $3.06 \mathrm{mmol} / \mathrm{l}$ in the 3rd and 15 th minute, respectively: $\mathrm{K}_{\mathrm{itt}} \mathrm{was}(\ln 6.51-\ln 3.06) \times 100 /(15-3)=$ $0.06291 \times 100=6.291 \mathrm{mmol} / 1 / \mathrm{min}$.

Another three indirect markers of insulin resistance were used:

- fasting insulin level,

- fasting C-peptide level,

- SHBG (sex hormone binding globulin) which 
Table 1. Basic demographics, metabolic parameters (including non-cholesterol sterols) and the insulin sensitivity markers in particular studied groups.

\begin{tabular}{|c|c|c|c|c|}
\hline & non-DM & BD & DM & p-value \\
\hline Sample size & 72 & 117 & 63 & - \\
\hline Men & $37(51 \%)$ & $89(76 \%)$ & $37(59 \%)$ & $0.0012 *$ \\
\hline Age (years) & $58.1 \pm 13.35$ & $39.7 \pm 10.62$ & $59.6 \pm 7.74$ & 0.0001 \\
\hline$B M I\left(\mathrm{~kg} / \mathrm{m}^{2}\right)$ & $28.85 \pm 8.05$ & $26.23 \pm 3.97$ & $32.82 \pm 7.43$ & 0.0001 \\
\hline Diabetes duration (years) & - & - & $8.6 \pm 7.43$ & - \\
\hline Glucose $(\mathrm{mmol} / \mathrm{l})$ & $5.42 \pm 0.71$ & $4.73 \pm 0.68$ & $9.36 \pm 3.12$ & 0.0001 \\
\hline HDL cholesterol $(\mathrm{mmol} / \mathrm{l})$ & $1.50 \pm 0.41$ & $1.46 \pm 0.33$ & $1.38 \pm 0.42$ & 0.0991 \\
\hline Triacylglycerols (mmol/l) & $3.35 \pm 1.03$ & $1.53 \pm 1.0$ & $2.28 \pm 1.52$ & 0.0001 \\
\hline$C R P(m g / l)$ & $4.74 \pm 5.40$ & $2.26 \pm 3.22$ & $5.25 \pm 5.61$ & 0.0001 \\
\hline Insulin $(\mathrm{pmol} / \mathrm{l})$ & $65.27 \pm 63.40$ & $56.61 \pm 58.9$ & $79.77 \pm 56.17$ & 0.0001 \\
\hline C peptide (nmol/l) & $0.94 \pm 0.52$ & $1.15 \pm 4.66$ & $1.0 \pm 0.47$ & 0.0001 \\
\hline SHBG $(\mathrm{nmol} / \mathrm{l})$ & $40.67 \pm 32.37$ & $40.67 \pm 32.37$ & $36.06 \pm 24.41$ & 0.1758 \\
\hline Quicki & $0.20 \pm 0.07$ & $0.20 \pm 0.04$ & $0.16 \pm 0.02$ & 0.0001 \\
\hline$H b A_{l C}(\%)$ & $5.55 \pm 0.44$ & $5.21 \pm 0.39$ & $7.82 \pm 1.78$ & 0.0001 \\
\hline Total cholesterol (mmol/l) & $5.34 \pm 1.12$ & $5.12 \pm 1.08$ & $5.26 \pm 1.65$ & 0.4845 \\
\hline LDL cholesterol (mmol/l) & $3.35 \pm 1.03$ & $3.18 \pm 0.97$ & $3.29 \pm 1.22$ & 0.4170 \\
\hline Lathosterol & $5.11 \pm 3.00$ & $6.75 \pm 7.87$ & $8.07 \pm 9.59$ & 0.0224 \\
\hline Squalene & $3.76 \pm 3.91$ & $2.31 \pm 2.89$ & $3.16 \pm 3.45$ & 0.0011 \\
\hline Sitosterol & $8.98 \pm 5.72$ & $8.18 \pm 5.55$ & $5.03 \pm 2.90$ & 0.0002 \\
\hline Campesterol & $9.80 \pm 5.43$ & $11.36 \pm 6.37$ & $6.89 \pm 5.97$ & 0.001 \\
\hline
\end{tabular}

Mean \pm S.D. are presented for continuous variables, frequency and percentage is presented for sex. Non-DM - non-diabetics with ischemic heart disease, BD - blood donors, DM - diet treated type2 diabetics, BMI - body mass index, CRP - C-reactive protein; $\mathrm{p}$-value is based on Kruskal-Wallis test, * p-value for sex is based on Fisher exact test.

is supposed to be a good biological marker of insulin resistance (Haffner 1996) being high in the insulinsensitive patients and low in the insulin-resistant patients.

Insulin, C-peptide and SHBG were measured by imunoradiometric assay (IRMA KIT, IMMUNOTECH, A Beckman Coulter Co., Prague). Plasma sterols were measured by gas chromatography and mass spectrometry after alkaline hydrolysis into hexane (Bakalár et al. 2003). Glucose, cholesterol, triglycerides and CRP (immunoturbidimetric method) were measured on an automatic analyzer Modular Roche Switzerland. $\mathrm{HbA}_{1} \mathrm{c}$ was assessed by the chromatographic method.

\section{Statistical analysis}

The descriptive statistics of mean \pm S.D. was used to show all measured parameters. Wilcoxon rank sum test was used to compare the two groups with $\mathrm{K}_{\text {itt }}$ assessments. Kruskal-Wallis test was employed to compare the three groups in terms of age, BMI, metabolic parameters (including non-cholesterol sterols), and insulin sensitivity markers. Fisher's exact test was used to compare proportions of male/female. Spearman correlation coefficient was used to analyze the correlation between the markers of the insulin resistance and the noncholesterol sterol levels.

Multiple regression models were used to assess the effect of independent predictors (metabolic and insulin sensitivity parameters) on the level of noncholesterol sterols, separately for each of the sterols and separately in each of the three groups. Predefined set of independent variables (consisting of Quicki index, BMI, lathosterol, $\mathrm{K}_{\mathrm{itt}}$ and CRP) was included in the model. Firstly, a full model with all variables was fitted and consequently the variables with nonsignificant regression coefficients were excluded from the final model (age, sex, cholesterol, triglycerides, glucose, $\mathrm{HbA}_{1 \mathrm{c}}$, noncholesterol sterols except lathosterol). In particular, no stepwise procedure was employed to find a subset of variables to be included in the model. Since the distribution of the sterols was skewed to the right, the 
Table 2. Spearman correlations between non-cholesterol sterols and insulin sensitivity markers (non-DM group).

\begin{tabular}{|c|c|c|c|c|}
\hline$n=72$ & Insulin & C peptide & SHBG & Quicki \\
\hline Lathosterol & -0.08821 & -0.04035 & -0.32522 & 0.07335 \\
\hline p-value & 0.4612 & 0.7365 & 0.0053 & 0.5403 \\
\hline Squalene & -0.05681 & 0.09857 & -0.19752 & 0.05134 \\
\hline p-value & 0.6355 & 0.4101 & 0.0963 & 0.6684 \\
\hline Sitosterol & 0.08988 & -0.02985 & 0.11321 & -0.09267 \\
\hline$p$-value & 0.4528 & 0.8035 & 0.3437 & 0.4388 \\
\hline Campesterol & -0.11884 & -0.26448 & 0.19986 & 0.11342 \\
\hline p-value & 0.3201 & 0.0248 & 0.0923 & 0.3428 \\
\hline
\end{tabular}

Spearman's correlation, $\mathrm{p}<0.05$ in bold.

Table 3. Spearman correlations between non-cholesterol sterols and insulin sensitivity markers (BD group).

\begin{tabular}{llcccc}
\hline $\mathbf{N}=\mathbf{1 1 7}$ & Insulin & C peptide & SHBG & Quicki & Kitt \\
\hline Lathosterol & 0.08695 & 0.07375 & -0.22428 & -0.07384 & -0.15435 \\
p-value & 0.3732 & 0.4503 & $\mathbf{0 . 0 2 0 2}$ & 0.4497 & 0.4329 \\
Squalene & 0.15333 & 0.01070 & -0.15855 & -0.15237 & 0.06133 \\
p-value & 0.1148 & 0.9129 & 0.1029 & 0.1172 & 0.9537 \\
Sitosterol & 0.08411 & -0.05772 & -0.10929 & -0.03864 & -0.0115 \\
p-value & 0.3890 & 0.5548 & 0.2625 & 0.6927 & 0.9537 \\
Campesterol & -0.13787 & -0.15928 & -0.02539 & 0.19013 & 0.08046 \\
p-value & 0.1567 & 0.1013 & 0.7952 & $\mathbf{0 . 0 4 9 8}$ & 0.684 \\
\hline
\end{tabular}

Spearman's correlation, $p<0.05$ in bold.

dependent variables in the linear models were logarithmically transformed. All referred $\mathrm{P}$ values are based on two-sided tests. $\mathrm{P} \leq 0.05$ values were considered statistically significant. Due to the exploratory character of the study the results were not adjusted for multiplicity.

The statistical analyses were performed using the SAS software (version 8.2, SAS Institute Inc., Cary, $\mathrm{NC}, \mathrm{USA}$ ).

\section{Results}

As expected, no difference between the groups was found in the total cholesterol and LDL cholesterol levels (Table 1). Similarly, no difference between the groups was found in SHBG and HDL cholesterol levels. All other typical components of metabolic syndrome (triacylglycerols, glucose, $\mathrm{HbA}_{1} \mathrm{c}, \mathrm{CRP}$ ) and insulin sensitivity markers were significantly different between the groups. The three groups also differed in noncholesterol sterol levels (Table 1).
The $\mathrm{K}_{\mathrm{itt}}$ index was significantly different between the blood donors $(5.64 \pm 2.42 \mathrm{mmol} / \mathrm{l} / \mathrm{min})$ and the diabetics $\quad(1.92 \pm 1.55 \mathrm{mmol} / \mathrm{l} / \mathrm{min}) \quad(\mathrm{p}<0.0001)$, showing a high insulin sensitivity in the blood donor groups and low sensitivity in diabetics. No differences in fat and fiber scores were found. Diabetics did not eat higher amounts of fruit and vegetables.

The Spearman's correlation matrices (exploring the relationship between sterols and insulin resistance markers) for the three investigated groups are shown in Tables 2, 3 and 4.

Only two significant associations consistent with Simonen's hypothesis (the low absorption and the high cholesterol synthesis in the insulin-resistant patients) were found in the group of patients without diabetes (Table 2) - a negative correlation of SHBG and lathosterol and a negative correlation of campesterol and C peptide. No contradictory results compared to Simonen's hypothesis were found.

In the group of blood donors (Table 3), only two 
Table 4. Spearman correlations between non-cholesterol sterols and insulin sensitivity markers (DM group).

\begin{tabular}{|c|c|c|c|c|c|}
\hline$N=63$ & Insulin & C peptide & SHBG & Quicki & Kitt \\
\hline Lathosterol & 0.09695 & -0.07010 & -0.08355 & -0.15877 & 0.02077 \\
\hline$p$-value & 0.4535 & 0.5882 & 0.5186 & 0.2177 & 0.8815 \\
\hline Squalene & -0.01763 & -0.17025 & -0.11859 & 0.02183 & 0.35628 \\
\hline$p$-value & 0.8918 & 0.1858 & 0.3586 & 0.8662 & 0.0082 \\
\hline Sitosterol & -0.05883 & 0.01723 & 0.18850 & -0.01738 & -0.10483 \\
\hline$p$-value & 0.6497 & 0.8943 & 0.1423 & 0.8934 & 0.4506 \\
\hline Campesterol & -0.13493 & -0.04944 & 0.33048 & 0.14888 & 0.00938 \\
\hline p-value & 0.2957 & 0.7027 & 0.0087 & 0.2481 & 0.9463 \\
\hline
\end{tabular}

Spearman's correlation, $\mathrm{p}<0.05$ in bold.

Table 5. Regression models of campesterol, squalene and sitosterol levels in the DM group.

\begin{tabular}{|c|c|c|c|c|c|c|}
\hline & \multicolumn{6}{|c|}{ Dependent variable* } \\
\hline Analysis of variance & \multicolumn{2}{|c|}{$\mathrm{r}^{2}=0.17, \mathrm{p}=0.001$} & \multicolumn{2}{|c|}{$\mathrm{r}^{2}=0.12, \mathrm{p}=0.001$} & \multicolumn{2}{|c|}{$\mathrm{r}^{2}=0.16, \mathrm{p}=0.001$} \\
\hline $\begin{array}{l}\text { Independent } \\
\text { variable }\end{array}$ & $\begin{array}{l}\text { Estimated } \\
\text { coefficient }\end{array}$ & p-value & $\begin{array}{l}\text { Estimated } \\
\text { coefficient }\end{array}$ & $\mathrm{p}$-value & $\begin{array}{l}\text { Estimated } \\
\text { coefficient }\end{array}$ & p-value \\
\hline Intercept & -2.10724 & 0.0867 & 1.78832 & 0.0093 & 2.10141 & $<0.0001$ \\
\hline Quicki & 14.79054 & 0.0080 & excl. & excl. & excl. & n.s. \\
\hline$B M I$ & -0.03619 & 0.0347 & -0.03984 & 0.0339 & -0.03984 & 0.0339 \\
\hline Lathosterol & -0.02637 & 0.0143 & excl. & excl. & -0.06242 & 0.0017 \\
\hline Kitt & excl. & n.s. & 0.14882 & 0.0462 & 0.14882 & 0.0462 \\
\hline$C R P$ & excl. & n.s. & excl. & excl. & -0.05528 & 0.0081 \\
\hline
\end{tabular}

* - all dependent variables were log-transformed, excl. - non-significant regressors were excluded from the model.

significant relations were found consistent with Simonen's hypothesis a negative correlation of SHBG and lathosterol and a positive correlation of campesterol and Quicki.

In the group of type 2 diabetics (Table 4), only one significant association was found consistent with Simonen's hypothesis - a positive correlation of SHBG and campesterol.

In the blood donors, there was no significant correlation between Kitt and non-cholesterol sterol level (Table 3), whereas a positive correlation between Kitt and squalene levels was found in the diabetics (Table 4).

Within each of the three groups and for each of the four non-cholesterol sterols separately, an exploratory multiple regression model was constructed to assess the effect of insulin sensitivity parameters, metabolic syndrome parameters and other non-cholesterol sterols. From the total of 12 models, significant associations were found in three models only in the diabetic group (Table 5). No significant relationship was found in the other two groups.

Some other components of the metabolic syndrome like CRP and BMI had some significant relationship to the non-cholesterol sterols level.

\section{Discussion}

Cholesterol is absorbed via a complicated mechanism and the dietary plant sterols interfere with this process. The circulating cholesterol levels are decreased by the consumption of margarine spreads that contain an increased amount of plant sterols. In practice, the plant 
sterols decrease cholesterol absorption. However, at the same time the level of circulating plant sterols reflects the cholesterol absorption from the gut. Two ratios have also been proposed for the assessment: sitosterol/cholesterol and campesterol/cholesterol (Miettinen and Gylling 2003). Our results support Simonen's hypothesis that the low cholesterol absorption and its high synthesis may be part of the metabolic syndrome. We found an increased synthesis of cholesterol in diabetics, as suggested by the high levels of lathosterol and a decrease in the cholesterol absorption, reflected in the low levels of sitosterol and campesterol. The positive correlation of $\mathrm{K}_{\mathrm{itt}}$ and squalene levels in diabetics does not reflect decreased insulin synthesis with increasing insulin resistance, as squalene levels can be influenced both by cholesterol absorption and cholesterol synthesis. The finding of normal HDL cholesterol levels in diabetic and nondiabetic patients with ischemic heart disease (not significantly different from blood donors) is not in accordance with the concept of the insulin resistance syndrome (Reaven 1988). This may be explained by the different sex distribution in our groups of patients.

The measurement of lathosterol levels could also be used to monitor the effect of statin therapy. An interesting mechanism of the enhanced cholesterol synthesis in diabetes was proposed - the succinate hypothesis (Fahien and MacDonald 2002). The same hypothesis could also explain the higher synthesis of triglycerides (Simonen et al. 2003). In contrast to type 2 diabetes, in type 1 diabetes the high absorption of cholesterol and sterols and the low synthesis of cholesterol was observed (Miettinen et al. 2004).

Our results seem to be consistent with the recent literature. Sutherland et al. (1992) found that the plasma levels of plant sterols (campesterol and sitosterol) were significantly lower in diabetics, and that insulinemia showed a negative correlation between plant sterol levels both in diabetics and non-diabetics. In diabetics, the insulinemia also correlated with lathosterol.

Simonen et al. (2002c) has recently reported that the cholesterol absorption efficacy was lower and the cholesterol synthesis was higher in obese subjects with diabetes than in those without diabetes, suggesting that diabetes modulates the cholesterol metabolism more than obesity alone.

Previously, we focused (Šmahelová et al. 2005) on the effect of statin treatment on plant sterol levels. Statins were found to be very effective in patients with high cholesterol synthesis. These results form a solid basis for the prevention of atherosclerosis and cardiovascular diseases in type 2 diabetics. The practical suggestion regarding plant sterols and stanols in the diet should be included (Gotto 2001).

Our study is the first attempt to evaluate the direct relation of non-cholesterol sterols to insulin resistance. We can conclude that only a weak association between the insulin resistance (the fundamental component of metabolic syndrome) and cholesterol metabolism was observed in any of the three groups we studied. The relationship between the mentioned abnormalities and metabolic syndrome is more complex. Further contributing factors could include obesity and systemic inflammation. Our results indicate that there exists a significant relationship between insulin sensitivity and indices of both increased cholesterol synthesis and decreased cholesterol absorption. Insulin resistance explains only a part of both abnormalities mentioned above.

\section{References}

BAKALÁŘ B, HYŠPLER R, PACHL J, ZADÁK Z: Changes in cholesterol and its precursors during the first days after major trauma. Wien Klin Wochensch 115: 775-779, 2003.

BONORA E, MOGHETTI P, ZANCANARO C, CIGOLINI M, QUERENA M, CACCIATORI V, CORGNATI A, MUGGEO M: Estimates of in vivo insulin action in man: comparison of insulin tolerance tests with euglycemic and hyperglycemic glucose clamp studies. J Clin Endocrinol Metab 68: 374-378, 1989.

BRODY T: Nutritional Biochemistry. Academic Press, San Diego, 1999, 1006 pp.

DEFRONZO RA, TOBIN JD, ANDRES R: Glucose clamp technique: a method for quantifying insulin secretion and resistance. Am J Physiol 237: E214-E223, 1979.

FAHIEN LA, MACDONALD MJ: Perspectives in diabetes. The succinate mechanism of insulin release. Diabetes 51: 2669-2676, 2002.

GOTTO AM: Dietary and other nondrug interventions. In: Contemporary Diagnosis and Management of Lipid Disorders. AM GOTTO (ed), Handbooks in Health Care, Newton, Pennsylvania, 2001, pp 94-138. 
GRACI S, BARATTA R., DEGANO C, IUPPA A, VIGNERI R, FRITTITTA L, TRISCHITTA V: The intravenous insulin tolerance test is an accurate method for screening a general population for insulin resistance and related abnormalities. J Endocrinol Invest 22: 472-475, 1999.

HAFFNER SM: Sex hormone-binding protein, hyperinsulinemia, insulin resistance and noninsulin-dependent diabetes. Horm Res 45: 233-237, 1996.

HIRST S, PHILLIPS DIW, VINES SK, CLARK PM, HALES CN: Reproducibility of the short insulin tolerance test. Diabetic Med 10: 839-842, 1993.

KEMPEN HJ, GLATZ JF, GEVERS LEUVEN JA, VAN DER VOORT HA, KATAN MB: Serum lathosterol concentration is an indicator of whole-body cholesterol synthesis in humans. J Lipid Res 29: 1149-1155, 1988.

KRISTAL AR, SHATTUCK AL, HENRY HJ: Patterns of dietary behavior associated with selecting diets low in fat: Reliability and validity of a behavioral approach to dietary assessment. J Amer Diet Assoc 90: 214-220, 1990.

KUKSIS A: Plasma non-cholesterol sterols. J Chromatogr 935: 203-236, 2001.

MIETTINEN TA: Detection of changes in human cholesterol metabolism. Ann Clin Res 2: 300-320, 1970.

MIETTINEN TA, GYLLING H: Synthesis and absorption markers of cholesterol in serum and lipoproteins during a large dose of statin treatment. Eur J Clin Invest 33: 976-982, 2003.

MIETTINEN TA, TILVIS RS, KESANIEMI A: Serum plant sterols and cholesterol precursors reflect cholesterol absorption and synthesis in volunteers of a randomly selected male population. Am J Epidem 131: 20-31, 1990.

MIETTINEN TA, GYLLING H, TUOMINEN J, SIMONEN P, KOIVISTO V: Low synthesis and high absorption of cholesterol characterize type 1 diabetes. Diabetes Care 27: 53-58, 2004.

REAVEN GM: Role of insulin resistance in human disease. Diabetes 37: 1595-1607, 1988.

SIMONEN P, GYLLING H, HOWARD A, MIETTINEN TA: Introducing a new component of the metabolic syndrome: low cholesterol absorption. Am J Clin Nutr 72: 82-88, 2000.

SIMONEN P, GYLLING H, MIETTINEN TA: Body weight modulates cholesterol metabolism in non-insulin dependent type 2 diabetics. Obes Res 10: 328-335, 2002a.

SIMONEN P, GYLLING H, MIETTINEN TA: Acute effects of weight reduction on cholesterol metabolism in obese type 2 diabetes. Clin Chim Acta 316: 55-61, 2002 b.

SIMONEN P, GYLLING H, MIETTINEN TA: Diabetes contributes to cholesterol metabolism regardless of obesity. Diabetes Care 25: 1511-1515, 2002c.

SIMONEN PP, GYLLING H, MIETTINEN TA: Diabetes and cholesterol metabolism. The succinate hypothesis. Diabetes Care 26: 550, 2003.

SUTHERLAND WH, SCOTT RS, LINTOTT CJ, ROBERTSON MC, STAPELY SA, COX C: Plasma non-cholesterol sterols in patients with non-insulin dependent diabetes mellitus. Horm Metab Res 24: 172-175, 1992.

ŠKRHA J, HAAS T, ŠINDELKA G, PRÁZNÝ M, WIDIMSKÝ J, CIBULA D, SVAČINA S: Comparison of the insulin action parameters from hyperinsulinemic clamps with homeostasis model assessment and QUICKI indexes in subjects with different endocrine disorders. J Clin Endocrinol Metab 89: 135-141, 2004.

ŠMAHELOVÁ A, ZADÁK Z, HYŠPLER R, HAAS T: An importance of vegetable sterols in diabetics (in Czech). Vnitřni lékařství 50: 147-152, 2004.

ŠMAHELOVÁ A, HYŠPLER R, HAAS T, ZADÁK Z, TICHÁ A: Effect of atorvastatin on non-cholesterol sterols in patients with type 2 diabetes mellitus and cardiovascular disease. Pharmacol Res 51: 31-36, 2005.

\section{Corresponding author}

A. Šmahelová, Department of Metabolic Care and Gerontology University Hospital, Charles University, Sokolská 581, 50005 Hradec Králové, Czech Republic. Fax +420-49-5832001. E-mail: smahelov@1fhk.cuni.cz 